\title{
Exercise: A Free Medicine of All Time
}

\author{
Faisal Muhammad (iD) $1,2,{ }^{*}$ \\ ${ }^{1}$ Department of Public Health, Faculty of Allied Health Sciences, Daffodil International University, Dhaka, Bangladesh \\ ${ }^{2}$ Department of Social Work, School of Liberal Arts and Social Sciences, University of Information Technology and Sciences, Dhaka, Bangladesh \\ "Corresponding author: Department of Public Health, Faculty of Allied Health Sciences, Daffodil International University, Dhaka, Bangladesh. Email: fokkanya@yahoo.com
}

Received 2020 June 08; Accepted 2020 June 10.

Keywords: Exercise, Health, Medicine, Diseases

\section{Dear Editor,}

Exercise is good to the well-being of people. Older people are susceptible to numerous chronic diseases. From a cardiovascular health data it was discovered that people with the best exercise test scores were less likely to die within the next 30 years than their counterpart. A research stated that as little as 15 minutes of exercise almost daily can help to lower the risk of cardiovascular diseases (1-3). Another study reveals that the physical inactivity is the primary cause of most chronic diseases across the globe (2, 4). It was evident that regular exercise can improve the brain functions as well as physical and mental functions (5). Strong and consistent evidence reveals that exercise has a significant impact in preventing symptoms and reducing back pain (6). An overview research conducted in United Kingdom reveals that exercise may have specific benefits in reducing the severity of chronic pain (7). The eye health of more than 40,000 men and women runners has been reviewed over several years and they had significantly lower rates of eye diseases than the general public. Each year in the US thousands of people are diagnosed with colon cancer. Many studies found that those that engaged in high intensity activities were less likely to develop colon cancer than others that had minimal workouts (8).

A new study involving thousands participants found that people with high fitness during their middle age were significantly less likely to die from heart disease in later life. Professionals recommends that starting to exercise early in life and continuing to do it often could protect both the mental and physical health of patients battling depression and facing heart disease risks. According to new research taking up a daily run could lower heart disease risks by almost 56 percent, and working out could be particularly good medicine for those with depression (9). A study reported that a moderate-intensity activities are so vital to our own health and can reduce the risk of death in older women. Health professional should be suggesting exercise for older women, in addition to other conventional treatments. Many studies reveals that intensity activity can have mental and physical health benefits (10). Everyone should stay active in order to stay healthy.

\section{Footnotes}

Authors' Contribution: All the work has been done by Faisal Muhammad.

Conflict of Interests: The author has no conflict of interest.

Funding/Support: There is no funding support.

\section{References}

1. Harvard heart letter. Exercise is still the best medicine. 2014, [cited 2020 Apr 30]. Available from: https://www.health.harvard.edu/stayinghealthy/exercise-is-still-the-best-medicine.

2. Booth FW, Roberts CK, Laye MJ. Lack of exercise is a major cause of chronic diseases. Compr Physiol. 2012;2(2):1143-211. doi: 10.1002/cphy.c110025. [PubMed: 23798298]. [PubMed Central: PMC4241367].

3. Pedersen BK, Saltin B. Exercise as medicine - evidence for prescribing exercise as therapy in 26 different chronic diseases. Scand $J$ Med Sci Sports. 2015;25 Suppl 3:1-72. doi: 10.1111/sms.12581. [PubMed: 26606383].

4. Knight JA. Physical inactivity: Associated diseases and disorders. Ann Clin Lab Sci. 2012;42(3):320-37. [PubMed: 22964623].

5. McPhee JS, French DP, Jackson D, Nazroo J, Pendleton N, Degens H. Physical activity in older age: perspectives for healthy ageing and frailty. Biogerontology. 2016;17(3):567-80. doi: 10.1007/s10522-016-96410. [PubMed: 26936444]. [PubMed Central: PMC4889622].

6. Gordon R, Bloxham S. A systematic review of the effects of exercise and physical activity on non-specific chronic low back pain. Healthcare (Basel). 2016;4(2). doi: 10.3390/healthcare4020022. [PubMed: 27417610]. [PubMed Central: PMC4934575].

7. Geneen LJ, Moore RA, Clarke C, Martin D, Colvin LA, Smith BH. Physical activity and exercise for chronic pain in adults: An overview of Cochrane Reviews. Cochrane Database Syst Rev. 2017;4. CD011279. doi: 
10.1002/14651858.CD011279.pub3. [PubMed: 28436583]. [PubMed Central: PMC5461882].

8. Clague J, Bernstein L. Physical activity and cancer. Curr Oncol Rep. 2012;14(6):550-8. doi: 10.1007/s11912-012-0265-5. [PubMed: 22945451]. [PubMed Central: PMC3490043].

9. Rahhal N. Exercise IS the best medicine: Working out combats depression and lowers heart disease risks, study finds. 2018. Available from:
https://www.dailymail.co.uk/health/article-5892393/Exercisebest-medicine-Working-combats-depression-lowers-heartdisease-risks.html.

10. Peluso MA, Guerra de Andrade LH. Physical activity and mental health: The association between exercise and mood. Clinics (Sao Paulo). 2005;60(1):61-70. doi: 10.1590/s1807-59322005000100012. [PubMed: 15838583]. 